\title{
Standardization and Chemical Analysis of Rasam: A South Indian Traditional Functional Food
}

\author{
Agilandeswari Devarajan', Muthu Kumaradoss Mohan Maruga Raja²
}

\section{Agilandeswari Devarajan', Muthu Kumaradoss Mo- han Maruga Raja²}

'Department of Pharmaceutics, Hillside College of Pharmacy and Research Centre, Bengaluru, Karnataka, INDIA. ${ }^{2}$ Department of Pharmacy, Centre for Research and Development, PRIST University, Thanjavur, Tamil Nadu, INDIA.

\section{Correspondence}

Agilandeswari Devarajan, Department of Pharmaceutics, Hillside College of Pharmacy and Research Centre, \#9, Raguhuvanahalli, Kanakapura Main Road, Bengaluru - 560 062, Karnataka, INDIA.

E-mail: agilandeswaridevarajan@gmail.com

\section{History}

- Submission Date: 27-03-2017;

- Review completed: 16-04-2017;

- Accepted Date: 02-05-2017.

DOI : 10.5530/pj.2017.5.93

Article Available online

http://www.phcogj.com/v9/i5

\section{Copyright}

(C) 2017 Phcog.Net. This is an openaccess article distributed under the terms of the Creative Commons Attribution 4.0 International license.

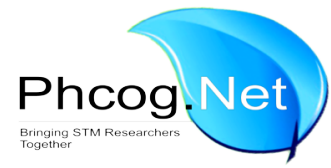

\begin{abstract}
Objective: The traditional Indian food is "functional" as it contains high amounts of dietary fiber, antioxidants, and probiotics. Rasam is a South Indian traditional spice soup. Spices are reputed to possess several pharmacological properties. Due to geographical, ethnical, and traditional differences, rasam recipe and the preparation process have a wide difference. Hence, the objective was to standardize rasam and then to perform a chemical analysis so that its pharmaceutical potential beyond nutritive effect can be explored. Materials and Methods: The quantity of ingredients and the process followed for preparing rasam by the 17 volunteers selected from in and around Vellore, Tamil Nadu was standardized. The proximate, nutritive, elemental, and phytochemical analysis were determined for the standardized rasam. Results: The total ash, acid insoluble ash, water soluble ash, and sulfated ash were found to be $1.7 \%$, $0.04 \%, 0.12 \%$, and $1.86 \%$, respectively. The extractive values such as water soluble, ethanol soluble, and ether soluble were found to be $4.5 \%, 3.93 \%$, and $0.61 \%$, respectively. The standardized rasam showed very low-energy content of $15.13 \mathrm{kcal} / 100 \mathrm{~g}$. Rasam contained alkaloids, tannins, saponins, flavonoids, terpenoids, steroids, glycosides. and volatile oil. Conclusion: The ingredients used in the preparation of rasam are medicinally claimed for various ailments, which makes it a traditional functional food. The standardized procedure provided tremendous opportunity to study the pharmaceutical potential in a systematic scientific way beyond its culinary and nutritive effect.
\end{abstract}

Key words: Chaaru, Elemental analysis, Nutritional value, Proximate analysis, Saaru, spices.

\section{INTRODUCTION}

The traditional Indian food is "functional" as it contains high amounts of dietary fiber (whole grains and vegetables), antioxidants (spices, fruits, and vegetables), and probiotics (curds and fermented batter products). Due to the chemical diversification of the ingredients, these Indian traditional functional foods exhibit the synergistic physiological effect. Epidemiological randomized clinical trials carried out in different countries have demonstrated numerous health effects related to functional food consumption such as reduction of cancer risk, improvement of heart health, stimulation of immune system, decrease of menopause symptoms, improvement of gastrointestinal health, maintenance of urinary tract health, anti-inflammatory effects, reduction of blood pressure, maintenance of vision, antibacterial effect, antiviral effect, reduction of osteoporosis, and anti-obese effect. ${ }^{1}$ Sambar, a South Indian traditional dish, has shown preventive effect against colon cancer. ${ }^{2}$ Rasam, also called as chaaru or saaru, is a South Indian traditional spice soup, consumed especially in Tamil Nadu. Spices are used as flavoring agents throughout the world. In addition, they are reputed to possess several medicinal and pharmacological properties. ${ }^{3}$ It is traditionally prepared using tamarind juice as a base, with the addition of Indian sesame oil, turmeric, tomato, chili pepper, pepper, garlic, cumin, curry leaves, mustard, coriander, asafoetida, sea salt, and water. Rasam is a functional food since all the ingredients used in the preparation are medicinally claimed for various ailments.

In India, traditional foods are filled with multiples of uniqueness that are specific to each region. Similarly, the preparation process of rasam has a wide difference due to geographical, ethnical, and traditional variations exist in the ingredients used its quantity. There are more than 20 different types of rasam based on the permutation and combination of its constituent spices. ${ }^{4}$ Various literatures cite rasam as an effective treatment for cold, fever, flu, and diabetes ${ }^{3,5}$ but rasam used in those studies were consistent neither in their ingredients nor in the process of preparation. To explore the pharmaceutical potential of rasam beyond its culinary and nutritive effect, there arised a need to standardize the ingredients used, their quantity, and process involved in the preparation of rasam. Hence, the study was planned to standardize rasam prepared in and around a particular geographical location, Vellore, Tamil Nadu, India, and also to per- 
form a chemical analysis so that its pharmaceutical potential can be consistently explored in a scientific way.

\section{MATERIALS AND METHODS}

\section{Location}

Approximately $33 \mathrm{~km}$ in and around Vellore in four directions East, West, North, and South were set as zone of distribution for the study. Vellore was selected as a center of distribution (CoD). Around Vellore, 17 places (four in each direction) were selected. Seventeen volunteers one from each selected place were chosen as samples for studying the process involved in the preparation of rasam based on the following criterions;

Females above 50 years

Natives to the region for at least three generations, and Vegetarians.

\section{Standardization}

The quantity of ingredients and the process used for the preparation of rasam by the 17 volunteers were partially optimized. All the 17 volunteers were provided with the sufficient quantity of ingredients (q.s.) and utensils to prepare a fixed volume $(500 \mathrm{~mL})$ of rasam in their traditional way. The ingredients were purchased from Arokya Organic Shop, Vellore. All utensils used for the preparation of rasam were of stainless steel of 316 grade. The whole processes of the preparation of rasam were divided into five different stages as stepwise standardization;

- Preparation of tamarind fruit pulp mixture (T1)

- Preparation of tomato fruit mixture (T2)

- Preparation of spice mixture (T3),

- Preparation of all mixture (T4), and

- Preparation of final product (T5).

The data regarding the accurate quantity of the ingredients used and the exact processes followed by the 17 volunteers in the preparation of rasam were individually recorded as phase wise, and standardized to a fixed recipe with a precise process. Statistical analysis was performed using GraphPad Instat Version 4 software, and the values were expressed as mean \pm standard deviation.

\section{Chemical analysis}

\section{Proximate analysis of standardized rasam}

The standardized rasam was subjected to proximate analysis such as total ash, acid insoluble ash, water soluble ash, sulfated ash, water-soluble extractive, ethanol soluble extractive, and ether soluble extractive values. $^{6}$

\section{Nutritive and elemental analysis of standardized rasam}

The quantity of water, carbohydrates, proteins, fats, fibers, and vitamins present in standardized rasam was estimated. Moreover, the quantity of calcium, magnesium, sodium, potassium, phosphorus, sulfur, chloride, iron, molybdenum, boron, copper, manganese, zinc, nickel, aluminum, and selenium present in standardized rasam were also estimated..$^{7-11}$

\section{Preliminary qualitative phytochemical analysis of standardized rasam}

The standardized rasam was studied for the presence and absence of secondary metabolites such as alkaloids, tannins, saponins, flavonoids, terpenoids, steroids, glycosides, and volatile oil. ${ }^{12}$

\section{RESULTS}

The details of the selected 17 places, its coordinates, direction, and distance from the CoD are as shown in Table 1. The biological source of ingredients used for the preparation of rasam is as shown in Table 2. The quantity of ingredients and the processes used for the preparation of T1, $\mathrm{T} 2, \mathrm{~T} 3, \mathrm{~T} 4$, and $\mathrm{T} 5$ by 17 volunteers is as shown in Tables 3-5.

The procedure for standardized rasam is as follows;

$\mathrm{T} 1-6.88 \mathrm{~g}$ of tamarind fruit pulp was immersed in $450 \mathrm{~mL}$ of water for 10 min which was then hand crushed for 45 times and strained. The strained liquid was rinsed with $5 \mathrm{~mL}$ water into which $0.4 \mathrm{~g}$ of turmeric powder and $4 \mathrm{~g}$ of sea salt was added.

T2 $-82.44 \mathrm{~g}$ of fresh tomato fruits was hand crushed for 60 times. The crushed fruit was rinsed with $5 \mathrm{~mL}$ of water.

T3 - $1.33 \mathrm{~g}$ of pepper drupes was crushed in a mortar and pestle for 85 times. $2.67 \mathrm{~g}$ of cumin fruits was added over to the crushed pepper drupes and crushed for 100 times. To the above-crushed mixture, $0.82 \mathrm{~g}$ of chili pepper was added and crushed for 50 times. To the above mixture, $9.63 \mathrm{~g}$ of garlic cloves was added and crushed for 90 times.

T4 - Tomato fruit mixture (T2) was rinsed with $10 \mathrm{~mL}$ of water, and spice mixture (T3) was rinsed with $10 \mathrm{~mL}$ of water. Both rinsing were added to tamarind fruit pulp mixture (T1).

$\mathrm{T} 5-4 \mathrm{~mL}$ of Indian sesame oil was heated at $60^{\circ} \mathrm{C}$ for $2 \mathrm{~min}$. After $5 \mathrm{~s}$, $0.82 \mathrm{~g}$ of mustard seeds were added. After $3 \mathrm{~s}, 1.53 \mathrm{~g}$ of whole chili pepper was added. After $2 \mathrm{~s}, 0.61 \mathrm{~g}$ of curry leaves was added. Immediately, all mixture (T4) was rinsed with $20 \mathrm{~mL}$ of water and added. The whole liquid was allowed to boil for a $5 \mathrm{~min}$. After $5 \mathrm{~min}, 1.50 \mathrm{~g}$ of coriander leaves was added. When the liquid frothed, $0.05 \mathrm{~g}$ of asafoetida was added, and the heating was switched off to yield the final product.

The ash values of standardized rasam such as total ash, acid insoluble ash, water soluble ash, and sulfated ash were found to be $1.7 \%, 0.04 \%$, $0.12 \%$, and $1.86 \% \mathrm{w} / \mathrm{w}$, respectively. The extractive values such as water soluble, ethanol soluble, and ether soluble were found to be $4.5 \%, 3.93 \%$ and $0.61 \% \mathrm{w} / \mathrm{w}$, respectively. The nutritional value of standardized rasam per $100 \mathrm{~g}$ is expressed in Table 6. Preliminary qualitative phytochemical analysis of standardized rasam results confirmed the presence of alkaloids, tannins, saponins, flavanoids, terpenoids, steroids, glycosides, and volatile oil.

\section{DISCUSSION}

The traditional foods of each specific region of India are primarily a component of its culture. If these traditional foods are to be standardized, it has to be evaluated within a specific region. Hence, a specific geographical location Vellore, Tamil Nadu was selected to standardize rasam. For better efficiency of the standardization process, 17 volunteers were selected based on specific criterions within the selected geographical zone. The required ingredients and the necessary utensils were provided to all 17 volunteers to maintain uniformity of the study. The 17 preparations from each volunteer were qualitatively and quantitatively recorded in phase wise. The quantity of ingredients and the processes followed by the 17 volunteers involved in the preparation of rasam were combined and standardized to a fixed recipe. Based on the derived recipe, a standardized rasam was prepared and further subjected to chemical analysis. Ash values identified the presence of inorganic radicals such as carbonates, phosphates, silicates and silica of sodium, potassium, magnesium, and calcium. Total ash and sulfated ash of the standardized rasam indicated high quantity of carbonates and oxides. Inorganic variables such as calcium oxalate, silica, carbonate content affected the "total ash" values. Such variables were removed by the acid treatment (as they are soluble in hydrochloric acid) and then acid-insoluble ash value was determined. 


\section{Table 1: The selected places, its coordinates, direction, and distance from the center of distribution}

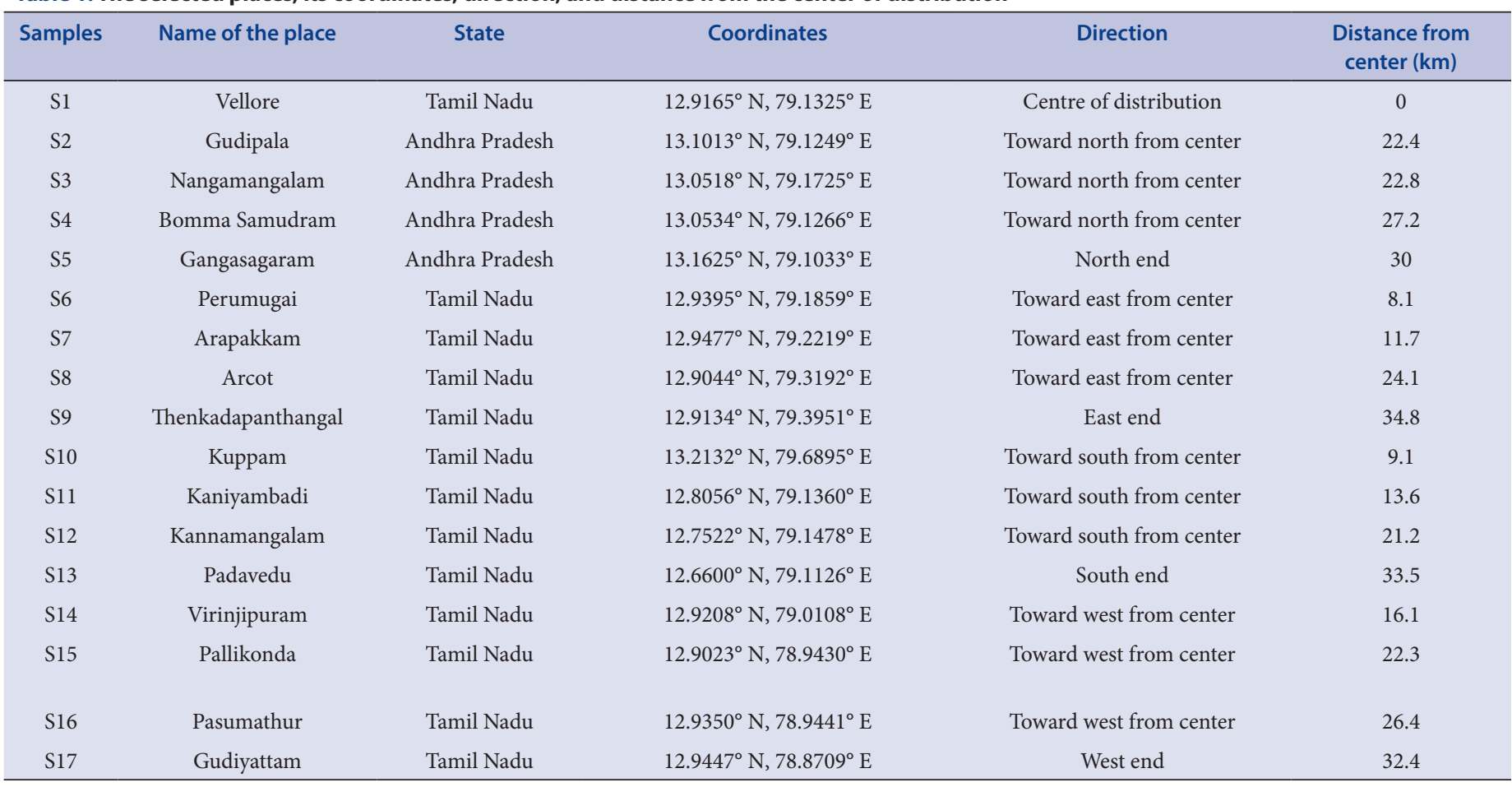

Table 2: Biological source of the ingredients used in the preparation of rasam

\begin{tabular}{|c|c|c|c|c|}
\hline Common names & Morphological part used & $\begin{array}{l}\text { Nature of the } \\
\text { material }\end{array}$ & Botanical name & Family \\
\hline Tamarind & Ripped fruit pulp & Dried & Tamarindus indica $\mathrm{L}$. & Fabaceae \\
\hline Turmeric & Rhizome powder & Dried & Curcuma longa $\mathrm{L}$. & Zingiberaceae \\
\hline Sea salt & NA & Solid & NA & NA \\
\hline Tomato & Ripped fruit & Fresh & Solanum lycopersicum L. & Solanaceae \\
\hline Chili pepper & Crushed fruit of long chili pepper & Dried & Capsicum annuum $\mathrm{L}$. & Solanaceae \\
\hline Cumin & Ripped fruit & Dried & Cuminum cyminum $\mathrm{L}$. & Apiaceae \\
\hline Garlic & Bulb & Dried & Allium sativum $\mathrm{L}$. & Amaryllidaceae \\
\hline Black pepper & Unripe drupe & Dried & Piper nigrum $\mathrm{L}$. & Piperaceae \\
\hline Indian sesame oil & Seed & Oil & Sesamum indicum $\mathrm{L}$. & Pedaliaceae \\
\hline Black mustard & Seed & Dried & Brassica nigra $\mathrm{L}$. & Brassicaceae \\
\hline Chili pepper & Whole fruit of long chili pepper & Dried & Capsicum annuum $\mathrm{L}$. & Solanaceae \\
\hline Curry leaves & Leaves & Fresh & Murraya koenigii (L.) Sprengel & Rutaceae \\
\hline Portable water & NA & Liquid & NA & NA \\
\hline Coriander & Leaves & Fresh & Coriandrum sativum $\mathrm{L}$. & Apiaceae \\
\hline Asafoetida & $\begin{array}{c}\text { Dried latex (oleogum resin) exuded from } \\
\text { the rhizome or tap root }\end{array}$ & Powder & Ferula assa-foetida $\mathrm{L}$. & Apiaceae \\
\hline
\end{tabular}

NA: Not applicable

Low acid insoluble ash indicated less silicious materials such as earth or sand. Extractive values are useful as an evaluation tool to provide an idea about the nature of the chemical constituents present. Extractive values of standardized rasam showed very high quantity of polar and moderately polar constituents than nonpolar constituents.

Rasam is used as an appetizer, and its ingredients such as tamarind, turmeric, cumin, black pepper, curry leaves, and asafoetida are known for their digestive aid activity. There are various foods that create a neg- ative-calorie effect, which improves metabolism. These foods are usually plant-derived which are high in water content, rich in fibers, grains, legumes, vegetables, and fruits. A negative-calorie food is a food that requires more energy to digest the food than it provides. Standardized rasam almost contained water $(95.03 \%)$ with only $15.13 \mathrm{kcal}$. Hence, the body has to burn more energy to digest than it receives. However, there is no substantial evidence to comprehensively prove that rasam has negative calorie effect. 
Table 3: Quantity of ingredients used and the process involved to prepare the tamarind fruit pulp mixture (T1) and prepare the tomato fruit mixture (T2)

\begin{tabular}{|c|c|c|c|c|c|c|c|c|c|c|}
\hline Samples & $\begin{array}{l}\text { Tamarind } \\
\text { fruit pulp } \\
\text { (g) }\end{array}$ & $\begin{array}{c}\text { Volume of } \\
\text { soaking } \\
\text { water }(\mathrm{mL})\end{array}$ & $\begin{array}{l}\text { Soaking } \\
\text { time (s) }\end{array}$ & $\begin{array}{l}\text { Number } \\
\text { of hand } \\
\text { crushes }\end{array}$ & $\begin{array}{c}\text { Volume } \\
\text { of rinsing } \\
\text { water }(\mathrm{mL})\end{array}$ & $\begin{array}{l}\text { Turmeric } \\
\text { powder (g) }\end{array}$ & $\begin{array}{c}\text { Sea salt } \\
\text { (g) }\end{array}$ & $\begin{array}{l}\text { Tomato } \\
\text { fruit (g) }\end{array}$ & $\begin{array}{l}\text { Number } \\
\text { of hand } \\
\text { crushes }\end{array}$ & $\begin{array}{c}\text { Volume } \\
\text { of rinsing } \\
\text { water }(\mathrm{mL})\end{array}$ \\
\hline S1 & 7.2 & 439.4 & 573 & 39 & 4.2 & 0.39 & 3.85 & 78.62 & 57 & 4.5 \\
\hline S2 & 7.5 & 447.9 & 562 & 49 & 4.9 & 0.42 & 3.91 & 85.16 & 55 & 5.2 \\
\hline S3 & 6.8 & 452.4 & 588 & 47 & 5.5 & 0.46 & 4.17 & 79.28 & 59 & 4.6 \\
\hline S4 & 6.4 & 445.8 & 626 & 48 & 3.9 & 0.37 & 3.82 & 82.13 & 64 & 4.2 \\
\hline S6 & 7.3 & 435.7 & 568 & 51 & 4.5 & 0.41 & 4.23 & 79.45 & 54 & 4.8 \\
\hline S7 & 6.2 & 455.2 & 577 & 38 & 5.9 & 0.45 & 3.95 & 77.8 & 62 & 5.6 \\
\hline S8 & 7.5 & 450.2 & 594 & 46 & 4.8 & 0.34 & 3.84 & 82.75 & 55 & 4.7 \\
\hline S9 & 7.0 & 452.3 & 619 & 52 & 3.7 & 0.38 & 4.05 & 79.92 & 65 & 5.5 \\
\hline S10 & 6.6 & 461.3 & 632 & 43 & 5.8 & 0.31 & 3.84 & 85.77 & 54 & 5.1 \\
\hline S14 & 7.6 & 438.3 & 621 & 40 & 4.9 & 0.39 & 3.95 & 88.61 & 58 & 5.7 \\
\hline S15 & 6.7 & 456.6 & 602 & 42 & 5.4 & 0.45 & 4.10 & 83.36 & 66 & 5.2 \\
\hline S16 & 6.7 & 445.1 & 596 & 43 & 4.7 & 0.40 & 3.74 & 78.37 & 62 & 5.3 \\
\hline S17 & 6.3 & 455.2 & 604 & 47 & 5.3 & 0.46 & 3.91 & 86.04 & 58 & 4.7 \\
\hline Mean \pm SD & $6.88 \pm 0.52$ & $450.08 \pm 7.43$ & $599.71 \pm 23.6$ & $45.12 \pm 5.2$ & $4.98 \pm 0.73$ & $0.40 \pm 0.05$ & $4.00 \pm 0.18$ & $82.44 \pm 3.78$ & $59.65 \pm 3.92$ & $4.99 \pm 0.45$ \\
\hline
\end{tabular}

Table 4: Quantity of ingredients used and the process involved to prepare the spice mixture (T3) and prepare all mixture (T4)

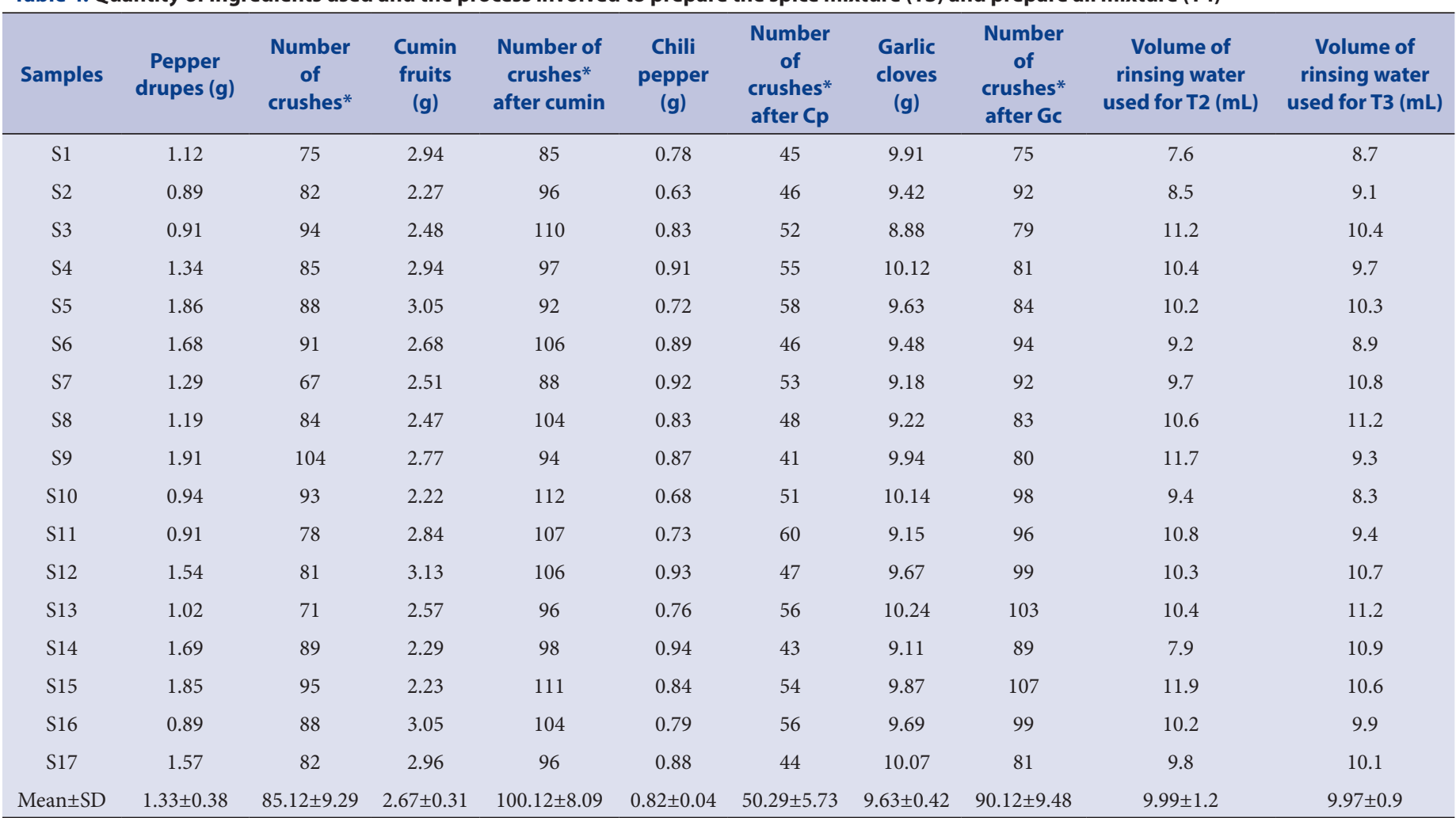

${ }^{*}$ Mechanical crushes. Cp: Chili pepper, Gc: Garlic cloves, SD: Standard deviation 


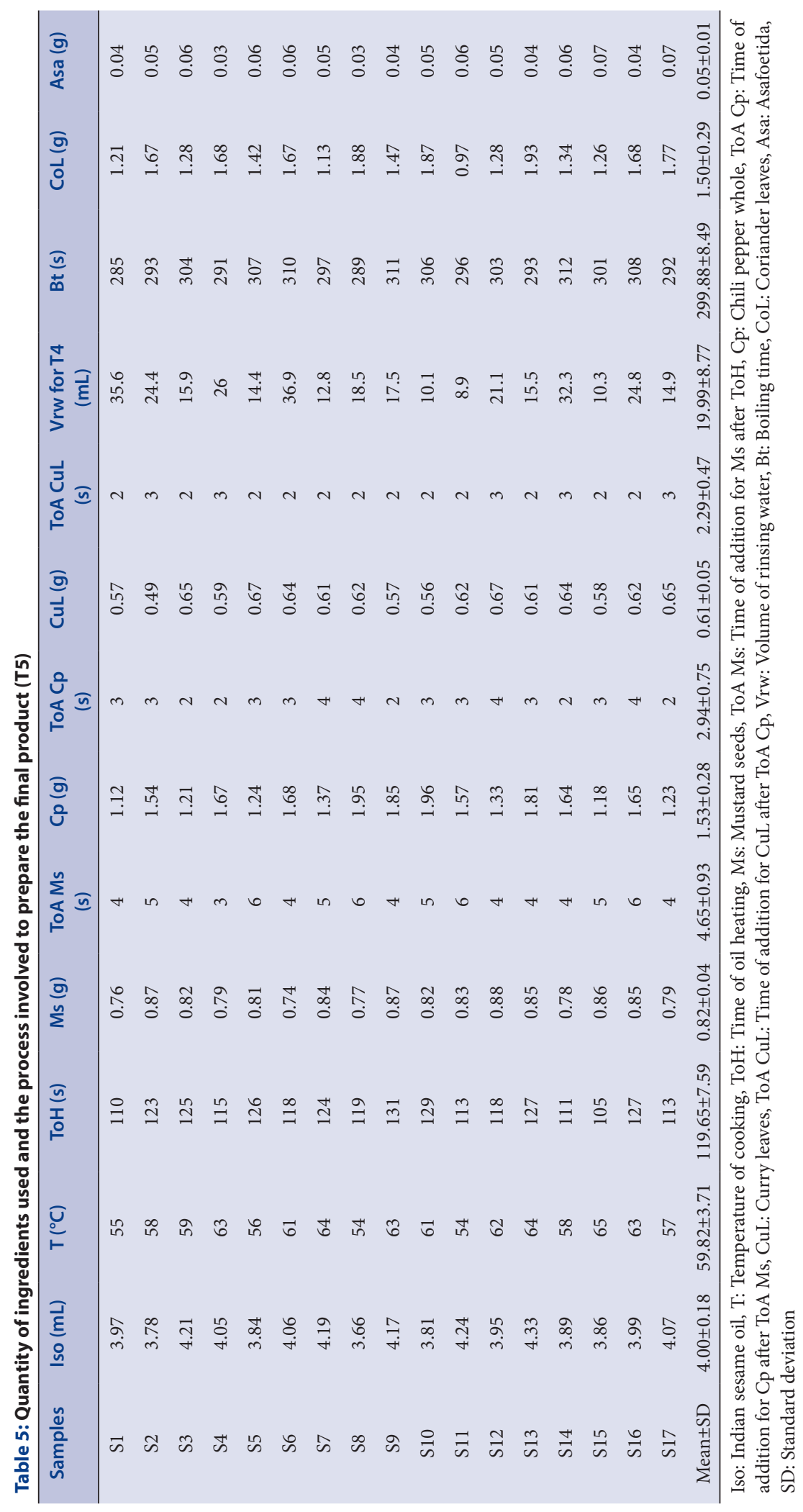

Rasam being an everyday traditional food, with high content of sodium, potassium, chloride, phosphorus and sulfur can be a daily dietary source. The presence of almost all the classes of secondary metabolites such as alkaloids, tannins, saponins, flavonoids, terpenoids, steroids, glycosides, and volatile oil is due to the chemical diversification in the ingredients used in rasam. These secondary metabolites may exert myriad physiological effects apart from digestive aid. The different ingredients used in rasam have been individually attributed to various pharmacological effects in preclinical and clinical studies. Hepatic tonic, anti-inflammatory, and antioxidant effect of tamarind fruit pulp; ${ }^{2,12}$ hepato-protective, 
Table 6: Nutritional value of standardized rasam (values expressed per $100 \mathrm{~g})$

\begin{tabular}{|c|c|c|}
\hline Nutrition facts & Values & Units \\
\hline \multicolumn{3}{|l|}{ Contents } \\
\hline Water & 95.03 & g \\
\hline Energy & 15.13 & kcal \\
\hline Proteins & 0.54 & g \\
\hline Total lipid (fat) & 0.41 & g \\
\hline Carbohydrate & 2.32 & g \\
\hline Fiber, total dietary & ND & NA \\
\hline \multicolumn{3}{|l|}{ Minerals } \\
\hline Calcium, $\mathrm{Ca}$ & ND & NA \\
\hline Iron, $\mathrm{Fe}$ & 0.5 & $\mu \mathrm{g}$ \\
\hline Magnesium, Mg & ND & NA \\
\hline Phosphorus, $\mathrm{P}$ & 10 & $\mathrm{mg}$ \\
\hline Potassium, K & 100 & $\mathrm{mg}$ \\
\hline Sodium, $\mathrm{Na}$ & 410 & $\mathrm{mg}$ \\
\hline Zinc, Zn & 6 & $\mu \mathrm{g}$ \\
\hline Copper, $\mathrm{Cu}$ & 0.8 & $\mu \mathrm{g}$ \\
\hline Manganese, $\mathrm{Mn}$ & $<0.25$ & $\mu \mathrm{g}$ \\
\hline Selenium, Se & $<0.25$ & $\mu \mathrm{g}$ \\
\hline Sulfur, S & 400 & $\mu \mathrm{g}$ \\
\hline Chloride, $\mathrm{Cl}$ & 750 & $\mathrm{mg}$ \\
\hline Molybdenum, Mo & $<0.25$ & $\mu \mathrm{g}$ \\
\hline Boron, B & $<0.25$ & $\mu \mathrm{g}$ \\
\hline Nickel, Ni & $<0.25$ & $\mu \mathrm{g}$ \\
\hline Aluminum, $\mathrm{Al}$ & $<0.25$ & $\mu \mathrm{g}$ \\
\hline \multicolumn{3}{|l|}{ Vitamins } \\
\hline Vitamin C, total ascorbic acid & 0.58 & g \\
\hline Thiamine & ND & NA \\
\hline Riboflavin & ND & NA \\
\hline Niacin & ND & NA \\
\hline Vitamin B-6 & 0.34 & g \\
\hline
\end{tabular}

ND: Not detected, NA: Not applicable

antioxidant, anti-inflammatory, anticarcinogenic, and antimicrobial, antidiabetic, antiangiogenic effect and antithrombotic effect of turmeric; $;^{2,13}$ antioxidant and anticancer activity of chili pepper; ${ }^{2}$ anti-flatulent, hypoglycemic, hypolipidemic, antimicrobial, antioxidant, and cytotoxic activity of cumin;,2,14 hepato-protective, hypoglycemic, antihypertensive, antimicrobial, anticancer, and antioxidant effects of garlic bulbs; ${ }^{15,16}$ antioxidant, antimigraine, antiemetic, and antipyretic effect of black pepper; ${ }^{17,18}$ hypoglycemic effect of black mustard $;{ }^{19}$ hepato-protective, antimicrobial, anti-inflammatory, cardioprotective, hypoglycemic, and antipyretic activity of curry leaves; ${ }^{20-22}$ diuretic, antioxidant, and antiplatelet activity of coriander leaves; ${ }^{23,24}$ antiflatulent, anti-microbial, and antiasthmatic effect of asafoetida ${ }^{25}$ are been reported. These facts ascertain that rasam is a classical example of traditional functional food.

\section{CONCLUSION}

The processing followed in the formulation of rasam involved heating the spices in water and oil. This processing provided tremendous opportunity for a completely altered/different chemical composition of rasam.
The altered/different chemical composition of the rasam may be due to the loss of active principles or synergetic effect or breakdown of inactive metabolite to an active one or formation of new chemical entities. In the era of preventive medicines, a standardized procedure for the preparation of rasam can aid the exploration of its pharmaceutical potential in a systematic scientific way beyond its culinary and nutritive effect.

\section{Financial support and sponsorship}

Nil.

\section{ACKNOWLEDGEMENT}

The authors sincerely thank all the seventeen volunteers participated in the standardization study.

\section{CONFLICTS OF INTEREST}

There are no conflicts of interest.

\section{ABBREVIATION USED}

CoD: Center of distribution; T1: Preparation of tamarind fruit pulp mixture; T2: Preparation of tomato fruit mixture; T3: Preparation of spice mixture; T4: Preparation of all mixture; T5: Preparation of final product; Cp: Chili pepper; Gc: Garlic cloves; SD: Standard deviation; Iso: Indian sesame oil; T: Temperature of cooking; ToH: Time of oil heating; Ms: Mustard seeds; ToA Ms: Time of addition for Ms after ToH; ToA Cp: Time of addition for Cp after ToA Ms; CuL: Curry leaves; ToA CuL: Time of addition for CuL after ToA Cp; Vrw: Volume of rinsing water; Bt: Boiling time; CoL: Coriander leaves; Asa: Asafoetida.

\section{REFERENCES}

1. Choudhary R, Tandon RV. Consumption of functional food and our health concerns. Pak J Physiol 2009;5:76-83.

2. Prasad VG, Reddy N, Francis A, Nayak PG, Kishore A, Nandakumar K, et al. Sambar, an Indian dish prevents the development of dimethyl hydrazine-induced colon cancer: A preclinical study. Pharmacogn Mag 2016;12 Suppl 4:S441-5.

3. Parthasarathy VA, Chempakam B, Zachariah TJ, editors. Chemistry of Spices. $1^{\text {st }}$ ed. Oxfordshire: CAB International; 2008.

4. [Homepage on the Internet]. San Francisco: Wikimedia Foundation, Inc. Available from: https://www en wikipedia org/wiki/Rasam. [Last updated on 2017 Mar 04; Last cited on 2017 Mar 13]

5. Devi KK, Priyadharshini VP. Exploration of nutrient content of traditional recipes of Tamil Nadu with therapeutic properties. Int J Res Appl Nat Soc Sci 2014;2:1 12.

6. Ministry of Health and Family Welfare; Government of India, Department of Ayush. The Ayurvedic Pharmacopoeia of India, Part-II (Formulations). $1^{\text {st }}$ ed., Vol. II. New Delhi, India: Department of Ayush; 2008

7. Montagnac JA, Davis CR, Tanumihardjo SA. Nutritional value of cassava for use as a staple food and recent advances for improvement. Compr Rev Food Sci Food Saf 2009;8:181-94.

8. Bureau of Indian Standards, The National Standards Body of India. Indian Standard, Method for determination of protein in foods and feeds. IS: 7219-1973. New Delhi, India: Bureau of Indian Standards; 2005

9. Liang L, Wu X, Zhu M, Zhao W, Li F, Zou Y, Yang L. Chemical composition, nutritional value, and antioxidant activities of eight mulberry cultivars from China. Pharmacogn Mag 2012;8:215-24.

10. Misra A, Srivastava S, Verma S, Rawat AK. Nutritional evaluation, antioxidant studies and quantification of poly phenolics, in Roscoea purpurea tubers. BMC Res Notes 2015;8:324.

11. Ahmad M, Masood S, Sultana S, Hadda TB, Bader A, Zafar M. Report: Antioxidant and nutraceutical value of wild medicinal Rubus berries. Pak J Pharm Sci 2015;28:241-7.

12. Khandelwal KR. Practical Pharmacognosy Techniques and Experiments. $19^{\text {th }}$ ed. Pune: Nirali Prakashan; 2008.

13. Caluwe ED, Halamova K, Damme PV. Tamarindus indica L. - A review of traditional uses, phytochemistry and pharmacology. Afr Focus 2010;23:53-83.

14. Kondamudi PK, Kovelamudi H, Nayak PG, Rao MC, Shenoy RR. Curcumin half analog modulates interleukin-6 and tumor necrosis factor-alpha in inflammatory bowel disease. Pharmacogn Mag 2015;11 Suppl 2:S296-302.

15. Dwarampudi LP, Palaniswamy D, Nithyanantham M, Raghu PS. Antipsoriatic activity and cytotoxicity of ethanolic extract of Nigella sativa seeds. Pharmacogn 
Mag 2012;8:268-72.

16. Iyer A, Panchal S, Poudyal H, Brown L. Potential health benefits of Indian spices in the symptoms of the metabolic syndrome: A review. Indian J Biochem Biophys 2009;46:467-81.

17. Banerjee SK, Dinda AK, Manchanda SC, Maulik SK. Chronic garlic administration protects rat heart against oxidative stress induced by ischemic reperfusion injury. BMC Pharmacol 2002;2:16.

18. Butt MS, Pasha I, Sultan MT, Randhawa MA, Saeed F, Ahmed W. Black pepper and health claims: A comprehensive treatise. Crit Rev Food Sci Nutr 2013;53:875-86

19. Vijayakumar RS, Surya D, Nalini N. Antioxidant efficacy of black pepper (Piper nigrum $\mathrm{L}$.) and piperine in rats with high fat diet induced oxidative stress. Redox Rep 2004;9:105-10.

20. Khan BA, Abraham A, Leelamma S. Hypoglycemic action of Murraya koenigii (curry leaf) and Brassica juncea (mustard): Mechanism of action. Indian J Biochem Biophys 1995;32:106-8.

21. Sujatha R, Srinivas L. Modulation of lipid peroxidation by dietary components. Toxicol In Vitro 1995;9:231-6.

22. Suneetha WJ, Krishnakantha TP. Antiplatelet activity of coriander and curry leaf spices. Pharm Biol 2003;43:230-3.

23. Melo EA, Bion FM, Filho JM, Guerra NB. In vivo antioxidant effect of aqueous and etheric coriander (Coriandrum sativum L.) extracts. Eur J Lipid Sci Technol 2003; 105:483-7.

24. Srinivasan K. Role of spices beyond food flavoring: Nutraceuticals with multiple health effects. Food Rev Int 2005;21:167-88.

25. Mahendra P, Bisht S. Ferula asafoetida: Traditional uses and pharmacological activity. Pharmacogn Rev 2012;6:141-6.

\section{GRAPHICAL ABSTRACT}

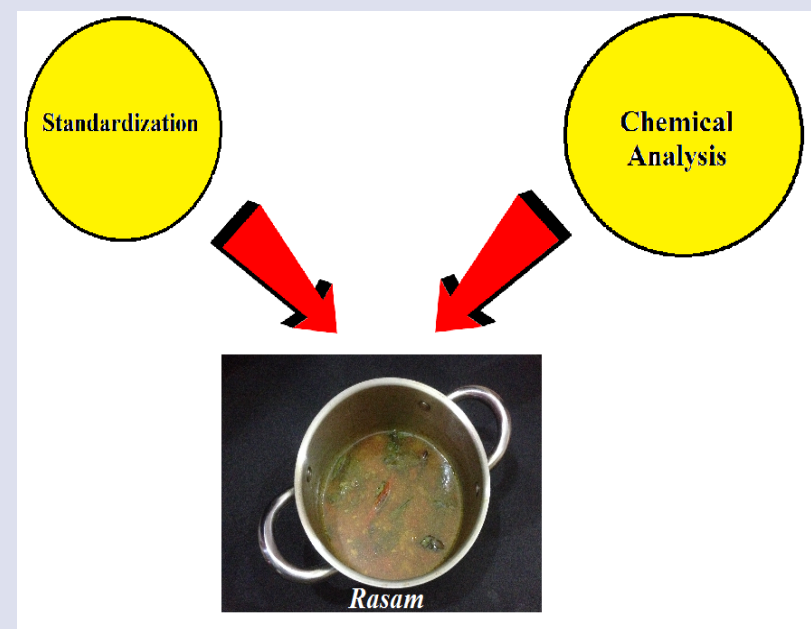

\section{HIGHLIGHTS OF PAPER}

- The ingredients used in the preparation of rasam are medicinally claimed for various ailments, which makes it a traditional functional food.

- Due to geographical, ethnical, and traditional differences, rasam recipe and the preparation process have a wide difference.

- The present study was aimed to standardize rasam and then to perform a chemical analysis.

- The standardized procedure provided tremendous opportunity to study the pharmaceutical potential in a systematic scientific way beyond its culinary and nutritive effect.

\section{AUTHOR PROFILE}

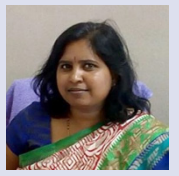

Agilandeswari Devarajan, M.Pharm., Associate Professor of Pharmaceutics, Hillside College of Pharmacy and Research Centre, Bengaluru, Karnataka, India. Research Scholar, Department of Pharmacy, Centre for Research and Development, PRIST University, Thanjavur, Tamil Nadu, India.

Field of specialization: Formulation of traditionally claimed herbal drugs and nanoparticle based targeted drug delivery.

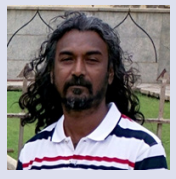

Muthu Kumaradoss Mohan Maruga Raja, Ph.D., Professor of Pharmacognosy, Department of Pharmacy, Centre for Research and Development, PRIST University, Thanjavur, Tamil Nadu, India.

Field of specialization: Drug discovery by systematic exploration and bioactivity guided isolation of active constituents and /or new chemical entities (NCEs) from traditionally claimed medicinal plants. Analytical method development for phytopharmaceuticals.

Cite this article : Devarajan A, Raja MK. Standardization and chemical analysis of Rasam: A South Indian traditional functional food. Pharmacognosy Journal. 2017;9(5):587-93. 